\title{
Creating a New Trail
}

\author{
Claudia Mitchell
}

\section{$\cos 80$}

The concerns addressed by the authors in this issue point to the need for a reimagining of girlhood as it is currently framed by settler and carceral states. To quote the guest editors, Sandrina de Finney, Patricia Krueger-Henney, and Lena Palacios, "The very notions of girl and girlhood are embedded in a colonial privileging of white, cis-heteropatriarchal, ableist constructs of femininity bolstered by Euro-Western theories of normative child development that were-and still are-violently imposed on othered, non-white girls, queer, and gender-nonconforming bodies." Indigenous-led initiatives in Canada, such as the Networks for Change: Girl-led 'from the Ground up' Policy-making to Address Sexual Violence in Canada and South Africa project, ${ }^{1}$ highlighted in four of the eight articles in this issue, along with the insights and recommendations offered in the articles that deal with the various positionalities and contexts of Latinx and Black girls, can be described as creating a new trail. In using the term trail, here, I am guided by the voices of the Indigenous researchers, activists, elders, and community scholars who participated in the conference called More Than Words in Addressing Sexual and Gender-based Violence: A Dialogue on the Impact of Indigenous-focused, Youthled Engagement Through the Arts on Families and Communities held in Montreal. ${ }^{2}$ Their use of the term trail suggests a new order, one that is balanced between the ancestors and spiritual teachings on the one hand, and contemporary spaces that need to be decolonized on the other with this initiative being guided by intergenerationality and a constant interrogation of language. The guest editors of this special issue and all the contributors have gone a long way on this newly named trail. 


\section{Notes}

1. Networks for Change and Well-being: Girl-led 'from the Ground up' Policy-making to Address Sexual Violence in Canada and South Africa' (Co Principal Investigators, Claudia Mitchell and Relebohile Moletsane) is supported through an International Development Research Centre (IDRC) grant (award number 107777-001) and a Social Sciences and Humanities Research Council of Canada (SSHRC) grant (award number 895-2013-3007).

2. The conference, held at McGill University, Montreal, Canada, on October 2-4, 2019, was an initiative of the More Than Words project funded by the Department of Women and Gender Equality (WAGE) of the Government of Canada. 